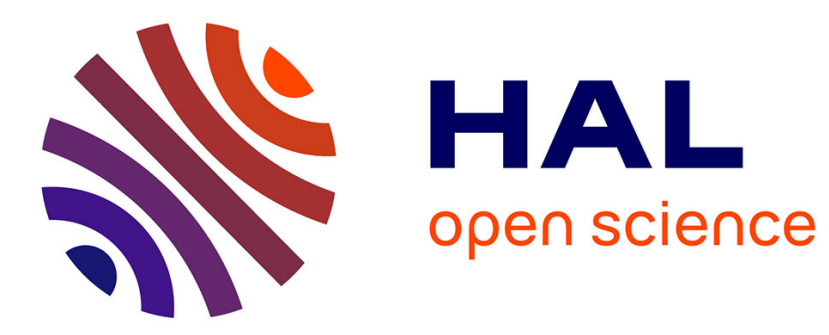

\title{
Eddy-Current Effects in Circuit Breakers During Arc Displacement Phase
}

Olivier Chadebec, Gerard Meunier, V. Mazauric, Yann Le Floch, Patrice Labie

\section{To cite this version:}

Olivier Chadebec, Gerard Meunier, V. Mazauric, Yann Le Floch, Patrice Labie. Eddy-Current Effects in Circuit Breakers During Arc Displacement Phase. IEEE Transactions on Magnetics, 2004, 40 (2), pp.1358-1361. 10.1109/TMAG.2004.824768 . hal-00289983

\section{HAL Id: hal-00289983 https://hal.science/hal-00289983}

Submitted on 24 Jun 2008

HAL is a multi-disciplinary open access archive for the deposit and dissemination of scientific research documents, whether they are published or not. The documents may come from teaching and research institutions in France or abroad, or from public or private research centers.
L'archive ouverte pluridisciplinaire HAL, est destinée au dépôt et à la diffusion de documents scientifiques de niveau recherche, publiés ou non, émanant des établissements d'enseignement et de recherche français ou étrangers, des laboratoires publics ou privés. 


\title{
Eddy-Current Effects in Circuit Breakers During Arc Displacement Phase
}

\author{
O. Chadebec, G. Meunier, V. G. Mazauric, Y. Le Floch, and P. Labie
}

\begin{abstract}
This paper deals with the modeling of eddy currents generated by arc motion during opening phases of low voltage circuit breakers. Two kinds of modeling are tested. While the first one consists in determining eddy currents in splitter plates, the second one is devoted to the calculation of eddy currents in electrodes. All simulations are carried out with a $T-\Phi$ finite-element method formulation and no new mesh at each time step is required.
\end{abstract}

Index Terms-Circuit breakers, eddy currents, finite-element method, magnetic forces.

\section{INTRODUCTION}

$\mathbf{T}$ HE goal of circuit breakers is to switch off currents in electric circuits. During this process, the contact opening ignites an electric arc which slides between two electrodes and is extinguished in splitter plates.

The force that yields the arc motion has two origins. The first one is the loop effect (the trend to increase the self-inductance of the circuit composed by the electrodes and the arc itself). The second one is due to the presence of ferromagnetic splitter plates which creates a classic reluctance variation effect and provides an arc attraction (see Fig. 1).

The calculus of the force acting on arc has led to numerous previous works [1]. In most part of them, only magnetostatic approaches are provided. However, the motion of the arc creates eddy currents in both electrodes and splitter plates. These eddy currents are expected to limit the force provided by both effects and decrease the performance of the current interruption process. In order to increase the efficiency of circuit breakers, it is then necessary to develop accurate models to calculate these eddy currents.

\section{Finite-Element Method (FEM) Formulations}

In this paper, we are focused on electrotechnical aspects. So, we have defined a very simple model for the arc. It is considered as a line with a square section and a constant translation velocity $\mathbf{v}$ is affected to it. Previous works have shown that eddy currents in arc can be neglected according to its low conductivity [2]. Thus, it is possible to consider that the current density in it is uniform.

Manuscript received July 1, 2003. This work was supported by Schneider Electric and CNRS.

O. Chadebec, G. Meunier and P. Labie are with the Laboratoire d'Electrotechnique de Grenoble, LEG, ENSIEG/INPG, 38402 Saint Martin d'Hères cedex, France (e-mail: chadebec@leg.ensieg.inpg.fr).

V. G. Mazauric is with Schneider Electric, Corporate Research Division, 38050 Grenoble cedex, France.

Y. Le Floch is with Cedrat, Zirst, 38246 Meylan, France.

Digital Object Identifier 10.1109/TMAG.2004.824768



Fig. 1. Circuit breaker with electrodes, splitter plates, arc and representation of loop effect.

Two kinds of description can be used to describe moving conductors [3]. In Eulerian description, the coordinate system of the problem is fixed. The velocity term is integrated into the formulation by assuming its opposite value to the electrode. Hence, the geometry as well as the physical properties are time independent which causes the transient term to vanish In such a description, the Maxwell equations system are reduced to

$$
\begin{aligned}
\operatorname{curl}(\rho \operatorname{curl} \mathbf{H}+\mathbf{v} \times(\mu \mathbf{H})) & =0 \\
\operatorname{div}(\mu \mathbf{H}) & =0
\end{aligned}
$$

where $\rho$ is the resistivity of the material and $\mu$ is its permeability. In the air, we only have to solve (2).

Notice that in the Eulerian approach is easy to implement and only one resolution is needed. It leads to low CPU computation times but it is limited to invariant geometries. In particular, in our application electrodes must be considered as infinite and splitter plates effects cannot be taken into account. Moreover, Eulerian description can lead to numerical instabilities for high Peclet numbers and then requires upwind elements [4].

To take into account the specific geometry of our device, it is necessary to develop a Lagrangian description, where each moving conductor has its own coordinate system. A step by step resolution is adopted and, at each time step, the arc position is shifted of a distance of $\mathrm{v} \cdot \Delta \mathrm{t}$. The following equations are solved by a finite difference time-stepping approach with an implicit scheme. For translation motion, we have in rigid body conducting regions

$$
\begin{aligned}
\operatorname{curl}(\rho \operatorname{curl} \mathbf{H}) & =-\frac{\mathrm{d}(\mu \mathbf{H})}{\mathrm{dt}} \\
\operatorname{div}(\mu \mathbf{H}) & =0
\end{aligned}
$$

where $\rho$ is the resistivity of the material, $\mu$ is the permeability, and $\mathbf{H}$ is the magnetic field. $\mathrm{d} / \mathrm{dt}$ denotes the convective derivative. In the air, we only have to solve (4). 
To solve (1) and (2) or (3) and (4), a $\mathbf{T}-\Phi$ formulation based on the electric vector potential $\mathbf{T}$ and scalar magnetic potential $\Phi[5]$ with nodal approximation is used. The expression of the field and the current are then

$$
\begin{aligned}
\mathbf{H} & =\mathbf{T}-\operatorname{grad} \Phi \\
\mathbf{J} & =\operatorname{curl} \mathbf{T} .
\end{aligned}
$$

This formulation has two advantages. First, it leads to one unknown per node in the air region and, second, it ensures high current density conservation in conductors that is convenient for further Lorentz force calculations.

To limit CPU times and validate our model, we have decided to separate the evaluation of eddy current in splitter plates and in electrodes. It is based under the assumption that eddy currents in one region do not influence the other one. In the third part, we are interested by the eddy-current distribution in splitter plates. This geometry being noninvariant, only a Lagrangian approach can be applied. In the fourth part, eddy-current effects in electrodes are under study. We will see that we can apply both Eulerian and Lagrangian descriptions if we consider infinite electrodes. Both approaches will be compared.

\section{EDDY-CuRRENT EFFECT IN SPlitTer Plates}

In this section, eddy currents in the electrodes are neglected. Only reluctance effect is then evaluated. It is then possible to take into account the effect of the source current (electrodes + arc) with a simple moving inductor. A Lagrangian description of motion is then adopted.

To restore the Ampere's law, it is convenient to reduce the potential $\Phi$ with respect to the current in the inductor. We have in the air region

$$
\mathbf{H}=\mathbf{T}_{\mathbf{0} \text { ind }}-\operatorname{grad} \Phi
$$

where $\mathbf{T}_{0 \text { ind }}$ is the field created by the inductor and calculated by Biot and Savart's formula.

In the splitter plates region, in order to circumvent the so-called cancellation error in ferromagnetic part, $\Phi$ is reduced only with respect to eddy currents with a jump condition at the interface with the air region [6]

$$
\mathbf{H}=\mathbf{T}-\operatorname{grad} \Phi .
$$

It remains to introduce (7) and (8) in (3) and (4). At each time step, the position of the inductor is changed and a new $\mathbf{T}_{0 \text { ind }}$ is calculated. After resolution, $\mathbf{T}$ and $\Phi$ are obtained. Eddy-current density in splitter plates is then calculated with the following expression:

$$
\mathbf{J}=\operatorname{curl} \mathbf{T} \text {. }
$$

This formulation has been tested on a geometry composed of splitter plates. Fig. 2 shows an example of eddy-current distribution obtained for a linear ferromagnetic material.

Then, the Lorentz force acting on the arc (i.e., $\mathbf{J} \times \mathbf{B}$ integrated on the volume of the arc) can be calculated for different velocity and compared to static reluctant effect and loop effect (Fig. 3.). Let us notice that for a velocity of $80 \mathrm{~m} / \mathrm{s}$, the attractive force due to reluctant effect is divided by two. However, the loop effect remains the more dominant effect until the insertion in the splitter plates.

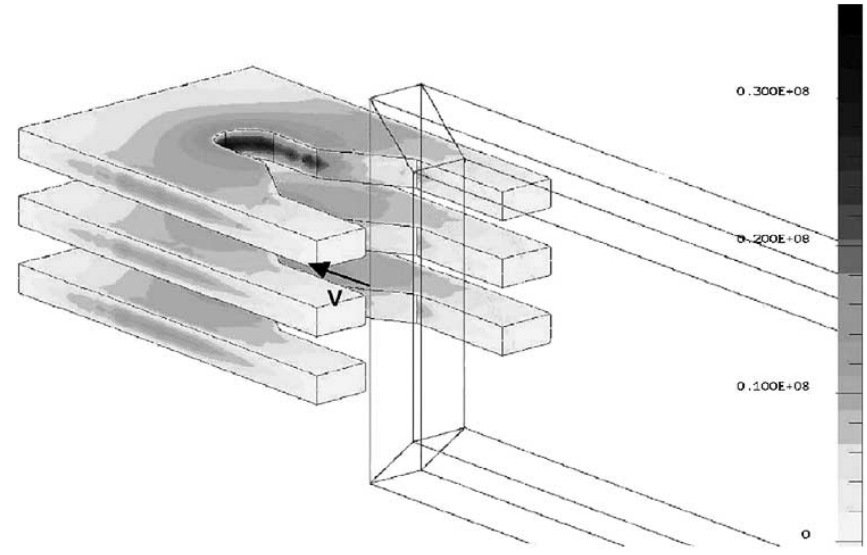

Fig. 2. Eddy-current density $\left(\mathrm{A} / \mathrm{m}^{2}\right)$ in splitter plates when the arc enters the slots $\left(v=20 \mathrm{~m} / \mathrm{s}, \rho=1.10^{-7} \Omega \mathrm{m}, \mu_{\mathrm{r}}=1000, \mathrm{I}=1000 \mathrm{~A}\right)$.



Fig. 3. Force $(\mathrm{N})$ acting on $\operatorname{arc}$ versus $\operatorname{arc}$ position $(\mathrm{I}=1000 \mathrm{~A})$. Comparison between loop effect without any splitter plate (analytical calculation [2]), magnetostatic force due to splitter plates and magnetostatic force combined with eddy-current effects for several velocity.

\section{EDDY-CURRENTS EFFECTS IN ELECTRODES}

In this section, we are focused on eddy currents in electrodes (i.e., the loop effect). Splitters plates are then replaced by air. Like in previous section, it is necessary to restore Ampere's theorem. Two kinds of conductors generate source field: the arc and the electrodes. The arc is still without any eddy currents and an inductor model it. Its effect $\mathbf{T}_{0 \text { arc }}$ is still calculated by Biot and Savart's formula. However, it is necessary to introduce another auxiliary vector potential $\mathbf{T}_{0 \text { elec }}$ which is created by the two electrodes. Two approaches are possible to calculate $\mathbf{T}_{0 \text { elec }}$.

The first one is to use an inductor, which crosses the electrode and carries total current [7]. $\mathbf{T}_{0 \text { elec }}$ is then calculated by Biot and Savart's law. The expression of $\mathbf{T}_{0}$ is then strictly equivalent to $\mathbf{T}_{0 \text { ind }}$ in previous section. The main advantage of this approach is its convenience of implementation to take into account the motion of the arc. However, this method needs a high mesh density everywhere in the conductor and is often too much memory consuming.

We preferred to use a preliminary FEM static current flow resolution. This is carried out by imposing the potential on the output and the input faces of the electrode and a Neumann 


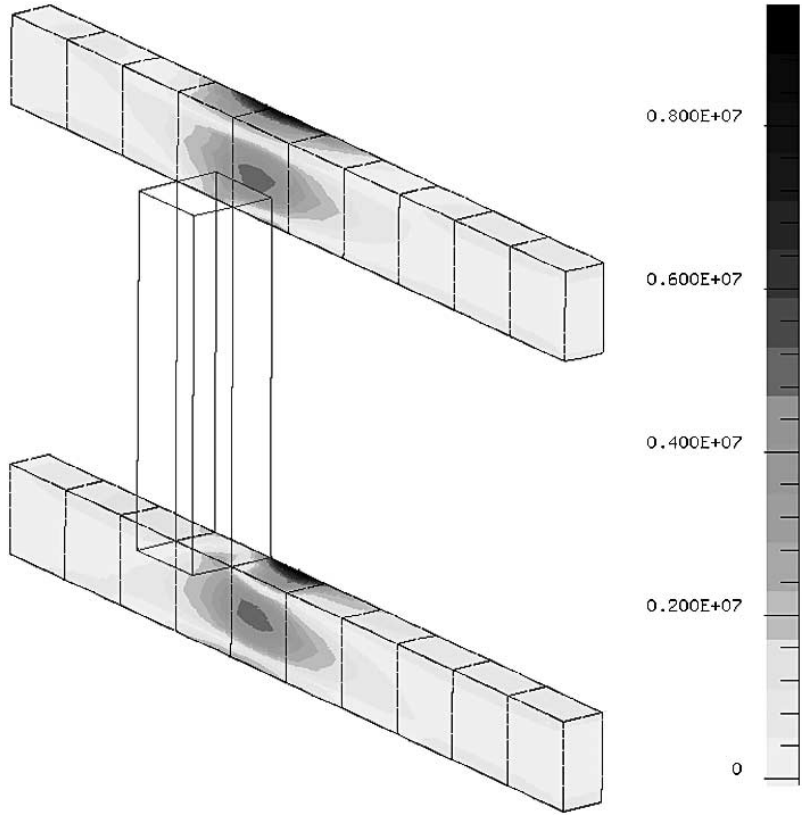

Fig. 4. Eddy-current density $\left(\mathrm{A} / \mathrm{m}^{2}\right)$ in electrodes $(\mathrm{v}=20 \mathrm{~m} / \mathrm{s}$, $\left.\rho=2.10^{-8} \Omega \mathrm{m}, \mu_{\mathrm{r}}=1, \mathrm{I}=1000 \mathrm{~A}\right)$ with a Lagrangian description. Only half geometry is represented.

boundary condition elsewhere. We obtain in each electrode $i$ a static current density $\mathbf{J}_{0 \mathrm{i}}$. $\mathbf{T}_{\text {Oeleci }}$ is then calculated by solving a second FEM system

$$
\left(\operatorname{curl} \mathbf{T}_{\mathbf{0}} \text { eleci }-\mathbf{J}_{\mathbf{0}} \mathbf{i}\right)^{2}=\mathbf{0} .
$$

The magnetic expression of the field in air region is

$$
\mathbf{H}=\mathbf{T}_{\mathbf{0}_{\text {arc }}}+\sum_{\mathrm{i}=1,2} \mathbf{T}_{\mathbf{0}_{\text {eleci }}}-\operatorname{grad} \Phi
$$

where $\Phi$ is then reduced with respect of current sources.

In the electrodes, $\Phi$ is reduced with respect to currents sources and eddy currents

$$
\mathbf{H}=\mathbf{T}_{\mathbf{0}_{\text {arc }}}+\sum_{\mathrm{i}=1,2} \mathbf{T}_{\mathbf{0}_{\text {eleci }}}+\mathbf{T}-\operatorname{grad} \Phi .
$$

After these two preliminary FEM resolutions, it remains to introduce:

- (11) and (12) in (1) and (2) (for an Eulerian description, i.e., an invariant geometry);

- (11) and (12) in (3) and (4) (for a Lagrangian description, i.e., the general case).

For the Eulerian description, two infinite electrodes are considered. This approach is simple to implement and constitutes a good validation for Lagrangian approach.

For the Lagrangian description, at each step, the arc is displaced to obtain a new $\mathbf{T}_{0 \text { arc }}$ and the boundary conditions of the static current flow resolution are changed to obtain new $\mathbf{T}_{0 \text { eleci }}$. Then, the global system is solved. For both descriptions, the total current in the electrode $i$ is

$$
\mathbf{J}=\operatorname{curl} \mathbf{T}+\mathbf{J}_{\mathbf{0}} \mathbf{i}
$$

We applied this approach to an electrode geometry (see Fig. 4), eddy-current distribution is then obtained and can be compared for both descriptions (Figs. 5 and 6). Eddy-current losses can be computed by integration over the electrode.

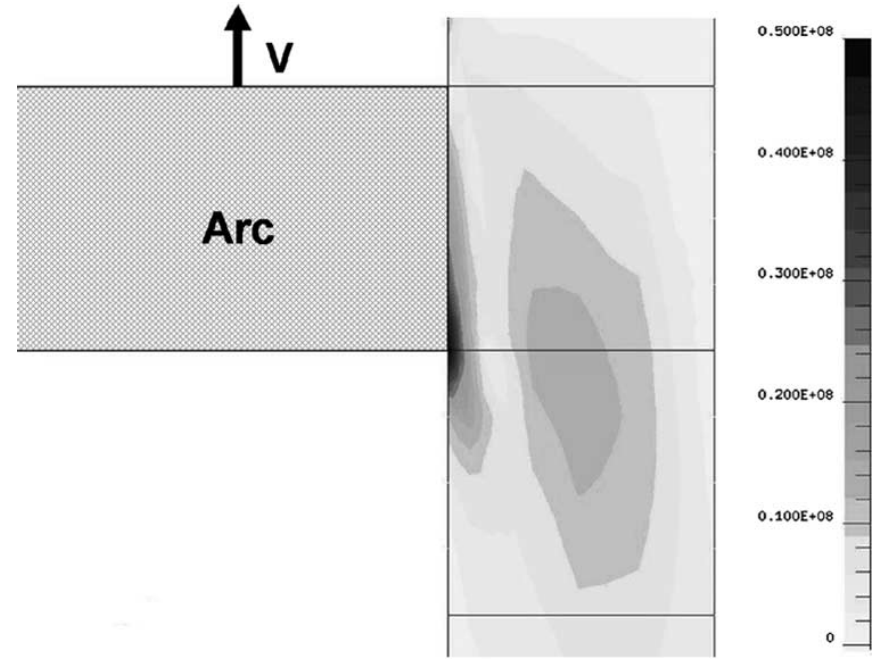

Fig. 5. Eddy-current density $\left(\mathrm{A} / \mathrm{m}^{2}\right)$ in electrodes for Eulerian description $\left(\mathrm{v}=40 \mathrm{~m} / \mathrm{s}, \rho=2.10^{-8} \Omega \mathrm{m}, \mu_{\mathrm{r}}=1, \mathrm{I}=1000 \mathrm{~A}\right)$. Only half geometry is represented.

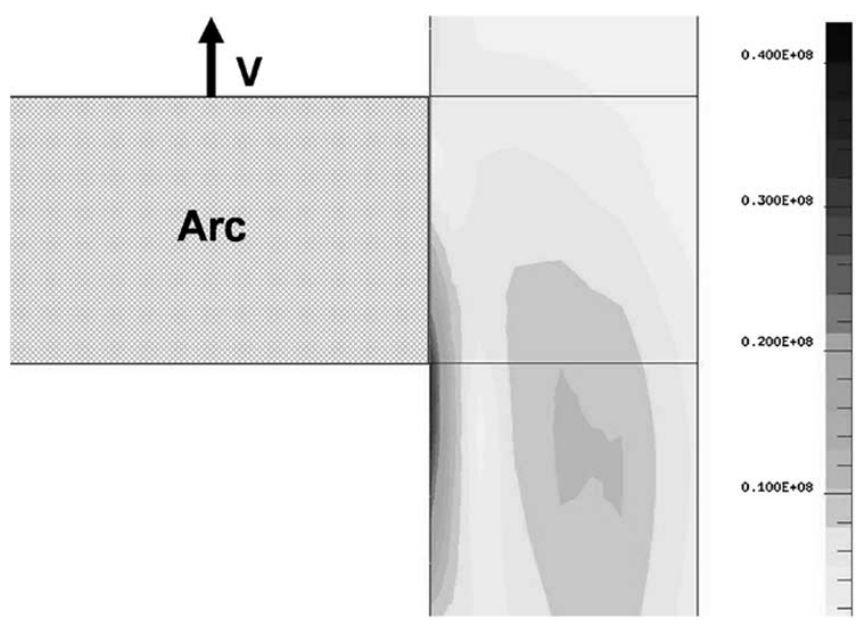

Fig. 6. Eddy-current density $\left(\mathrm{A} / \mathrm{m}^{2}\right)$ in electrodes for Eulerian description $\left(\mathrm{v}=40 \mathrm{~m} / \mathrm{s}, \rho=2.10^{-8} \Omega \mathrm{m}, \mu_{\mathrm{r}}=1, \mathrm{I}=1000 \mathrm{~A}\right)$. Only half geometry is represented.

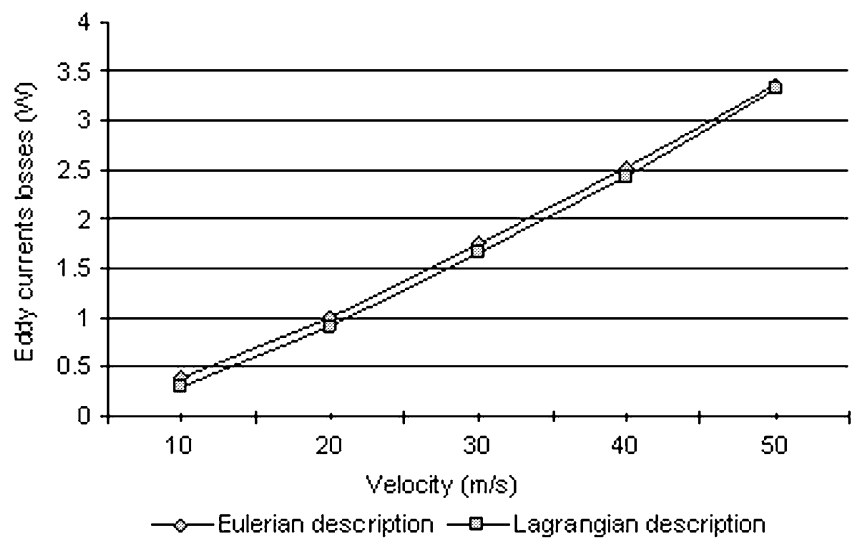

Fig. 7. Eddy-current losses versus velocity of the arc-Comparison between Lagrangian and Eulerian description $\left(\rho=2 \cdot 10^{-8} \Omega \mathrm{m}, \mu_{\mathrm{r}}=1, \mathrm{I}=1000 \mathrm{~A}\right)$.

Results shown on Fig. 7 present a good similarity. Moreover, force acting on arc due to eddy current versus velocity can be evaluated like in previous section (see Fig. 8). 


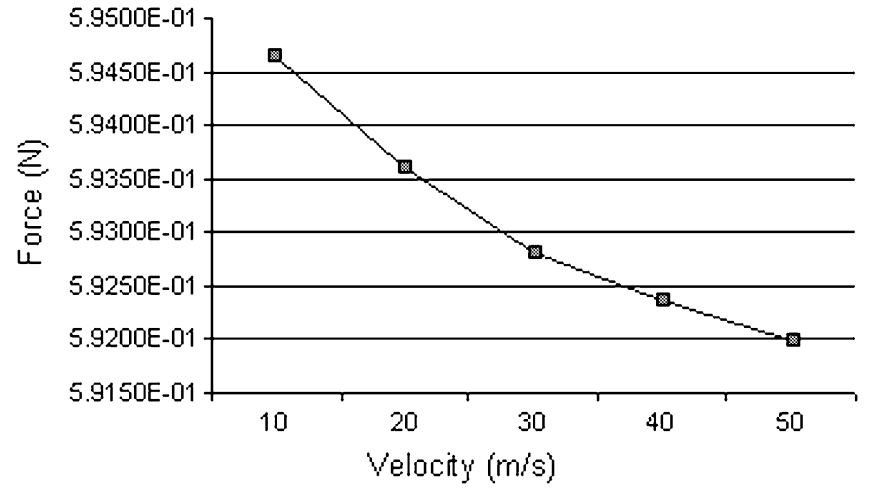

Fig. 8. Force currents acting on arc versus velocity $\left(\rho=2 \cdot 10^{-8} \Omega \mathrm{m}, \mu_{\mathrm{r}}=\right.$ $1, \mathrm{I}=1000 \mathrm{~A})$.

Let us notice that calculated forces are very low compared to the loop effect $(0.596 \mathrm{~N})$. We can then conclude that the eddy currents in electrodes can be negligible for velocity representative of an arc motion $(\mathrm{v}<100 \mathrm{~m} / \mathrm{s})$ and for this geometry of electrode.

\section{CONCLUSION}

We have developed new formulations to calculate eddy currents that appear in a circuit breaker during current interruption phases. These two formulations can be combined to obtain a global model in a Lagrangian approach. As we saw, eddy currents in splitter plates can create a sizeable force which reduces reluctant and loop effects. On the contrary, eddy currents in electrodes seems have a weak influence on arc motion.

The main advantage of this approach is that no new mesh at each time step is required. Then, it is possible to apply it easily to distorted arc and with nonconstant velocity. Further electric arc investigation could lead to a coupling between this approach and a more complex arc model.

Moreover, let us notice that this work can easily be applied to other devices like electrical railgun, for example.

\section{REFERENCES}

[1] H.-C. Song, U.-Y. Lee, S.-H. Kang, and K.-J. Lim, "3D Finite Elements Analysis of Magnetic Force on the Arc Chamber Design of Modeled Case Circuit Breaker," presented at the Numelec Conf., Poitiers, France, 2000.

[2] A. Slama, V. Mazauric, Y. Marechal, G. Meunier, and P. Wendling, "Electric railgun 3D modeling: Computation of eddy current and Lorentz force," IEEE Trans. Magn., vol. 37, pp. 139-142, Jan. 2001.

[3] K. Muramatsu, T. Nakata, N. Takahashi, and K. Fujiwara, "Comparison of coordinate systems for eddy current analysis in moving conductors," IEEE Trans. Magn., vol. 28, pp. 1186-1189, Mar. 1992.

[4] J. C. Heinrich, P. S. Huyakorn, O. C. Zienkiewicz, and A. R. Mitchell, "An upwind finite element scheme for two dimensinnonal convective transport term," Int. J. Num. Meth. Eng., vol. 11, pp. 131-143, 1977.

[5] O. Biro, K. Preis, W. Renhart, G. Vrisk, and F. Richter, "Computation of 3D current driven skin effect problem using current vector potential," IEEE Trans. Magn., vol. 29, pp. 1329-1332, Mar. 1993.

[6] Y. Le Floch, F. C. Guérin, X. Brunotte, and G. Meunier, "3-D Computation of magnetic anomaly due to a rotating plate in earth's magnetic field," IEEE Trans. Magn., vol. 38, pp. 553-556, Mar. 2002.

[7] A. Slama, V. Mazauric, G. Meunier, and Y. Marechal, "From an Eulerian Description the Electromagnetic Launcher," presented at the Compumag Conf., Evian, France, 2001. 